\title{
Food Patterns, Lifestyle, and Hypertension
}

\author{
Golnaz Arjmand, ${ }_{1}^{1}$ Mansour Shahraki, ${ }^{2,}$ Sara Rahati, ${ }^{1}$ and Touran Shahraki ${ }^{3}$ \\ ${ }^{1}$ Department of Clinical Nutrition, School of Nutrition Science and Dietetics, Tehran University of Medical Sciences, Tehran, IR Iran \\ ${ }^{2}$ Department of Nutrition, School of Medicine, Zahedan University of Medical Sciences, Zahedan, IR Iran \\ ${ }^{3}$ Department of Pediatrics, School of Medicine, Zahedan University of Medical Sciences, Zahedan, IR Iran \\ "Corresponding author: Mansour Shahraki, Department of Nutrition, School of Medicine, Zahedan University of Medical Sciences, Zahedan, IR Iran. E-mail: \\ shahrakimansour@yahoo.com
}

Received 2015 October 14; Accepted 2016 February 9.

\begin{abstract}
High blood pressure (BP) is considered as a strong predisposing factor for cardiovascular diseases (CVD) Environmental and genetic factors may have a role in high blood pressures. Nutrition has a potential role in the prevention of hypertension and its sequelae. Effect of lowering blood pressure by modification of complex dietary patterns may be the result of synergism between the various components of certain foods or food combinations rather than of the specific effect of a particular nutrient. Vegetarian Diet, Mediterranean Diet, and Dash Diet are three food patterns which have been associated with lowering BP. Vegetarian Diet are characterized by high intake of legumes, nuts, vegetables, and fruits. A relatively high polyunsaturated to saturated fat ratio will make by this kind of diet. Low fat content and high potassium, magnesium, and fiber content of this diet, all factors possibly cooperating to the reduction of blood pressure. Mediterranean Diet has low animal and dairy products as well as saturated fatty acids and cholesterol; it is rich in plant food, legumes, fiber, and antioxidant vitamins with olive oil as the main source of fat. The dietary approaches to stop hypertension (DASH) is a success process in control of hypertension, which emphasizes vegetables and fruits and dairy foods with low-fat, it also includes more nuts, poultry, fish, and, whole grains and lower amounts of red meat, fats, sweets, and sugar-containing beverages. DASH diet is poorer in total and saturated fat and cholesterol and richer in potassium, magnesium, calcium, and fiber in comparison to the habitual Western diet. In conclusion, although multiple dietary factors can influence on BP and each factor has a modest effect; the combined effects of those factors can be substantial. In the current study, we review food patterns, lifestyle, and their relationship with hypertension and the possible mechanisms involved.
\end{abstract}

Keywords: Food Patterns, Lifestyle, Hypertension

\section{Context}

Industrialized countries pay a heavy to cardiovascular diseases (CVDs) in terms of morbidity and mortality. In the past two decades in many developing countries an increasing load of CVD was shown. Therefore, CVD shows are considered as a main cause of disability, morbidity, and mortality worldwide [1]. Seventy-five percentage CVD results from high blood cholesterol, high blood pressure (BP), smoking, or their combination. In particular, high BP is a powerful risk factor for CVD, stroke, heart failure, renal failure, and deaths [1-4]. Specifically, nearly one billion individuals worldwide were affected by hypertension, thus hypertension representing the main cause of cardiovascular disease in the world. In addition, it is responsible for $13 \%$ of all deaths worldwide $[1,2,5]$. The prevalence of hypertension is similarly to increase with the population ages, as suggested by current data from the Framingham Heart Study;" whereby non-hypertensive individuals at 55 years of age have a 90\% lifetime risk to develop hypertension" [6]. Furthermore, high BP is less frequently a single risk factor but is more often accompanied by a bunch of other risk factors grouped under the definition of metabolic syndrome [7]. Elevated BP results from genetic factors, en- vironmental factors, and interactive interactions among these factors. Among of the environmental factors that affect BP (inactivity, diet, and psychosocial factors), factors that have a distinguished role on BP regulation is dietary factors [8]. It follows that nutrition has a great potential role in the prevention of hypertension and its comorbidity. Although the range of BP reduction from dietary manipulation is slightly greater in hypertensive individuals than in non-hypertensive, even an apparently small reduction in BP could have a great beneficial impact on the whole population [8].

The aim of this paper is to review present knowledge relating lifestyle modification and complex dietary patterns to the prevention and treatment of high BP.

\section{Evidence Acquisition}

We focus particularly on two dietary patterns habitually consumed by different populations/individuals in different parts of the world-the vegetarian diets and the Mediterranean diets- and an experimental diet that largely went into use, that is, the DASH diet. 


\section{Results}

\subsection{Lifestyle Modification}

Lifestyle modification, in last decade called nonpharmacologic therapy, has an important role in hypertensive and non-hypertensive individuals. In individuals with hypertension, lifestyle alteration act as a initial treatment before the start of drug therapy and as an auxiliary part of medication in persons already on drug therapy. In medication-controlled BP individuals, these therapies can facilitate drug descend and drug retreat in individuals who receive and keep lifestyle changes. To prevent hypertension, in non-hypertensive individuals, lifestyle modifications have a important role, and more extensively to reduce BP and thereby lower the risk of BP-related comorbiditie. Reduction in systolic BP to 3-mmHg can lead to an $8 \%$ and $5 \%$ reduction in stroke mortality and mortality from coronary heart disease respectively [9].

The effects of specific lifestyle factors that reduce BP highlight in the following sections: Increase in physical activity levels. Lowering in BP due to an increasing in level of physical activity was independent of concurrent changes in weight. An aerobic exercise intervention resulted in a 4 $\mathrm{mmHg}$ net reduction in systolic BP among individuals documented in a recent meta-analysis of 27 randomized trials [10]. Interestingly, independent of the exercise intensity to effect on BP change be magnitude. Increased physical level can promote initial weight loss and maintenance of it, in addition to a direct beneficial effect on BP. In aggregate, these findings are accompanied by recommendation of the US surgeon general; "persons exercise 30 minutes or more most, if not all, days of the week."

\subsection{Reducing Salt (Sodium Chloride) Intake}

The effect of high intake of sodium chloride on BP was shown in the past evidences. Document results from epidemiologic studies, animal studies, and clinical trials have documented that reduction in sodium intake can prevent hypertension (TOHP2, phase 2 of the trials of hypertension prevention) [11], promote control of hypertension in older-aged persons who use medication (TONE, trials of non-pharmacologic interventions in the elderly) [12], and in overweight individuals potentially can prevent cardiovascular events $[13,14]$. TOPH2 was shown that reduce in sodium intake can decrease the incidence of hypertension by approximately $20 \%$ alone or combined with weight loss. Reducing in BP and the need for antihypertensive medication in older persons documented in the TONE. In both trials reducing in total sodium intake to approximately 100 $\mathrm{mmol} / \mathrm{d}$ was shown. Such data support current guidelines to limit salt intake to $6 \mathrm{~g} / \mathrm{d}$, the equivalent of $100 \mathrm{mmol}$ of sodium (2400 mg) per day.

\subsection{Maintaining a Healthy Body Weight}

Observational and clinical trials studies indicate that BP and hypertension strongly associated with weight. High prevalence of overweight and obesity throughout the world showed the importance of this relationship. Weight reduction can lower BP was documented in every clinical trial that has examined the influence of weight loss on BP [15]. In one study that aggregated results across 11 weight loss trials, average systolic and diastolic BP reductions were 1.6/1.1 mmHg per kilogram of weight loss [16]. Lifestyle intervention trials have uniformly achieved shortterm weight loss. Shahraki et al., in clinical cross-sectional study showed that educational level, multiple pregnancies, marital status, and lack of exercise are some possible explanations for the obesity among Sistan and Baluchestan women [17]. In another study he showed that the rate of overweight/obesity among boys and girls was $8.9 \%$ and $10.3 \%$, respectively; Prevalence of overweight increased as the boys and girls approached adolescence and it was more prevalent among girls than boys. Prevalence of overweight was directly related to maternal education in this population [18]. In another clinical cross-sectional study he reported that the prevalence of cardiovascular risk factors increases with age. They emphasized that WC is a better index for predicting some cardiovascular risk factors in younger and middle-aged women; however, for older women, WHR was better [19].

\subsection{Moderating Alcohol Intake (Among Those Who Drink)}

Many epidemiologic studies have documented the relationship between elevated BP and high alcohol intake (typically three or more drinks per day). Reductions in alcohol intake can lower BP in non-hypertensive and hypertensive men who are heavy drinkers have also reported in trials. In the prevention and treatment of hypertension study, which studied moderate- to-heavy drinkers mentioned that; "a reduction in alcohol intake lowered BP to a small, non-significant extent” [20]. In aggregate, many documents support a recommendation to limit alcohol intake for men and women respectively to no more than two drinks and one per day among those who drink.

\subsection{Increasing Potassium Intake}

Increasing in levels of potassium intake is associated with low BP, whereas there is a direct relationship between salt intake and BP. A metnalysis of trials documented that supplementation of diet with potassium lowered BP [21]. Reducing systolic and diastolic BP to 4.4 and $2.5 \mathrm{mmHg}$ and to 1.8 and $1.0 \mathrm{mmHg}$ respectively was shown in hypertensives and non-hypertensives individuals by a typical dose of 60 to $120 \mathrm{mmol} / \mathrm{d}$ of supplemental potassium. 
From potassium intake reduction in BP in black people greater than whites. Because using diet can supply a high dietary intake of potassium rather than pills and because the sources of are variable, obtain potassium from food is better than supplements.

\subsection{Importance of Dietary Patterns}

Previous investigations of adolescent diet have tended to focus on intakes of individual foods or nutrients alone. However, in recent years, the use of dietary pattern analysis has become popular for characterizing the whole diet in combination, because this approach captures complex behaviors and potentially interactive and antagonistic effects among nutrients that might impact health outcomes $[22,23]$.

Vegetarian diet, Mediterranean diet, and Dash diet are three food patterns have been associated with lowering BP.

\subsection{Vegetarian Diet}

Anthropological and historical considerations of the diet of primitive men [24] as well as observational data on population groups where diets are plant-based [25, 26] clearly support the benefits on BP levels derived from the adherence to a vegetarian dietary regimen with no or very little amount of animal-based products [27]. Notably, when these individuals migrate to industrialized countries therefore changing their diet and lifestyles, their BP, and risk of hypertension increase [28]. However, even within industrialized societies, lifestyles and diet influence BP. To date, the most definitive and well-controlled observational data on the effects of vegetarian diets on BP come from studies of seventh-day Adventists. The seventh-

day Adventists are expected, by religious belief, to abstain from alcohol, nicotine, and caffeine and to follow a vegetarian diet supplemented with eggs and dairy products. In a cross-sectional analysis on a large cohort of 34 192 California seventh-day Adventists, the prevalence of hypertension was nearly double among Adventists who followed a diet similar to a typical American diet than in vegetarian adventists [29]. After adjustment for body weight, the effect was somewhat reduced, suggesting that the adherence to a vegetarian diet may be associated to lower body mass. Moreover, the Adventists showed a trend toward lower mortality from cancer, heart disease, and diabetes than non-Adventists living in the same communities. Cross-cultural studies have shown that the age-related increases in BP typically observed in developed societies is less evident in individuals adopting a vegetarian dietary style [30]. In summary, data from observational studies indicate that the SBP of vegetarians is $3-14 \mathrm{mmHg}$ lower and the DBP is 5 - $6 \mathrm{mmHg}$ lower than that of non-vegetarians.
Vegetarians also show lower prevalence of hypertension than non-vegetarians ( $2 \%-40 \%$ versus $8 \%-60 \%$, respectively) [22]. The number of randomized controlled trials of the effect of vegetarian diets on BP is quite small [27]. Overall they are supportive of the BP-lowering effects of vegetarian diets in both normotensive and hypertensive individuals. However, in most clinical studies, the adjustment for body weight reduced the effect of the intervention on BP, indicating that weight loss may be one of the mechanisms leading to the reduction of $\mathrm{BP}$, while apparently a reduction of sodium intake was not responsible for the observed effect.

Vegetarian diets are characterized by high intake of fruits, vegetables, legumes, and nuts, thus resulting in a relatively high polyunsaturated to saturated fat ratio, relatively low fat content and high potassium, magnesium, and fiber content, all factors possibly cooperating to the BP-lowering effect [31]. Additionally, the vegetarian lifestyle is often associated in Western societies to increased physical activity, abstention from alcohol and smoke, and adoption of relaxation techniques, possibly favorably acting on $\mathrm{BP}$ regulation. Fruits and vegetables are rich sources of antioxidants. John et al. [32] showed that, increased intake of fruits and vegetables was associated with decreases in SBP and DBP in both hypertensive and non-hypertensive individuals. Regulation of nitric oxide syntheses by antioxidants is a proposed mechanism by which vegetables may decrease BP [33]. The ability of dietary antioxidants to remove excess superoxide may be expected to potentiate the action of nitric oxide and reduce BP, because nitric oxide can be inactivated in vivo by the superoxide anion [33, 34]. A vegetarian diet can make reduction in body weight in overweight individuals and to the maintenance of a low body weight, with consequence of reductions in BP and in the risk of hypertension. However, reduced body weight is not the only mechanism by which vegetarian diets influence BP.

In conclusion, although the evidence suggests a BPlowering effect of a vegetarian diet, the high degree of intercorrelation among different dietary and non-dietary components hampers the identification of the factor or factors responsible for this effect. However, although specific recommendations for a vegetarian diet in the prevention/treatment of high BP cannot be made, this diet is largely consistent with most guidelines for the prevention and treatment of hypertension and CVD.

\subsection{Mediterranean Diet}

The story of the Mediterranean diet, first explored in the 1960s in the seven countries study, is considered the golden standard of healthy nutrition and it is associated with decreased morbidity and mortality, especially 
from cardiovascular causes [35-37]. This diet has consistently been associated with better health and longevity and the protective effects of the Mediterranean diet on coronary heart disease morbidity and mortality rates are well known [38-41]. This diet is low in animal and dairy products as well as saturated fatty acids and cholesterol; Mediterranean diet is rich in plant food, legumes, fiber, and antioxidant vitamins, whereas the main fat source of this diet is olive oil. Epidemiologic observations considering the complexity of the interplaying factors. This diet includes daily consumption of vegetables ( 2 - 3 servings), unrefined cereals and cereal products, fruit ( $4-6$ servings), dairy products (1 or 2 servings),olive oil, and red or white wine (1-2 wine glasses); weekly consumption of fish (4- 5 servings), potatoes ( $4-5$ servings), pulses, olives, and nuts (more than 4 servings) and sweets (1-3 servings)and eggs; monthly consumption of red meat and meat products (4-5 servings) [42]. The possible beneficial effect of the visible fat of the Mediterranean diet, monounsaturated olive oil, was investigated in a group of 23 hypertensive patients [43]. All of them were on stable antihypertensive treatment and had not changed their body weight in the last 6 months.

This study shows how a dietary pattern based on the use of olive oil ( $40 \mathrm{~g}$ daily for men and $30 \mathrm{~g}$ for women) was able to impede with BP control over long time in comparison to a dietary regimen whose lipid source was mainly represented by a similar amount of polyunsaturated sunflower oil. Three phases of this randomized single-blind clinical trial study includes: a 1-month run-in, a 6-month intervention period with monounsaturated or polyunsaturated dietary treatment, and a 6-month intervention period with the alternative dietary approach. Body weight did not change over this period. A significant reduction in the baseline dosage of antihypertensive drugs was observed (-48\%, 95\% confidence interval [CI], -25 to -71$)$, at the end of the olive oil dietary intervention, while at the end of the polyunsaturated treatment (-4\%, $95 \% \mathrm{CI},-24$ to 17$)$, no change was observed. The difference between the effects of the two dietary periods being statistically significant $(\mathrm{P}<005)$. In spite of the reduction of drug dosage, also reduction in BP levels at the end of the olive oil period is more significantly than the sunflower oil (127.84 \pm 14.8 $\mathrm{mmHg}$ versus $135.90 \pm 13.8 \mathrm{mmHg}, \mathrm{P}<05$ for SBP and $\mathrm{P}$ $<01$ for DBP). Poly-phenols with antioxidant properties in virgin olive oil may improve the endothelial function and effect on BP. These results, also confirmed by other studies [44].

\subsection{Dash Diet}

The story of the nutritional management of hypertension through modification of dietary patterns initiated from the DASH [45] and DASH-sodium trials [46]. The impressiveness of a dietary regimen similar to that adopted in the DASH diet has been emphasized in recent commanding reports $[8,47]$ DASH diet is emphasizes on fruits, vegetables, and low-fat dairy foods. Compared to the typical western diet, Dash diet also includes more whole grains, poultry, fish, and nuts, and lower amounts of fats, red meat, sweets, and sugar-containing beverages. DASH diet is poorer in total and saturated fat and cholesterol and richer in potassium, magnesium, calcium, and fiber in comparison to the Western diet. Actually, the BP lowering effect of complex dietary patterns is the result of the synergism between the different components of certain foods or food combinations rather than of the particular effect of a nutrient alone. The goal of the DASH diet was really to evaluate the effects on $\mathrm{BP}$ of a change in dietary patterns, rather than the effects of a change in a particular nutrient. Lowering systolic blood pressure by an average of about $6 \mathrm{~mm}$ $\mathrm{Hg}$ and diastolic pressure by about $3 \mathrm{mmHg}$ was observed by the DASH diet. The effect of the diet that was only higher than the typical American diet in fruits and vegetables on $\mathrm{BP}$ was about $3 \mathrm{mmHg}$ in systolic and $2 \mathrm{mmHg}$ reduction in diastolic pressure.

The DASH trial was even more effective for participants with blood pressure $140.90-159.99 \mathrm{mmHg}$ cause reducing in systolic and diastolic blood pressure by an average of 11 and $6 \mathrm{mmHg}$ respectively $[45,48]$ and within 2 weeks of starting the diet the reductions in blood pressure was happened. These surprising results presented significantly reduction in blood by the DASH diet and motivated the joint national committee on prevention, detection, evaluation, and treatment of high blood pressure to recommend the DASH diet to goal in blood pressure control [49]. What we earned from the DASH-Sodium study showed that reducing sodium intake could lower systolic and diastolic blood pressure significantly in both the control and DASH diet groups $[44,50]$. Key findings in that study includes :

-The DASH diet decrease blood pressure at any levels of sodium intake.

-Lowering sodium intake to the most recently recommended level $(2,400 \mathrm{mg})$ effectively reduced blood pressure in all participants.

-Lowering sodium intake to $1,500 \mathrm{mg}$ lowered blood pressure by twice in comparison to recommended level.

-Lowering sodium intake to $1,500 \mathrm{mg} /$ day in nonhypertensive subjects lowered blood pressure by 5.6/2.8 $\mathrm{mmHg}$ on the control diet and by 1.7/1.1 $\mathrm{mmHg}$ on the DASH diet.

-Lower sodium intake and the DASH diet when combined the effect of them on blood pressure become substantially greater. The combined effect of the DASH diet and lowering sodium intake to $1,500 \mathrm{mg}$ was a reduction of 
8.9/4.5 mmHg (7.1/3.7 mmHg in non-hypertensive subjects and $11.5 / 5.7 \mathrm{mmHg}$ in hypertensive subjects).

These findings have comprehensive implications. First, they supply a scientific basis for a dietary sodium aim lower than most recently recommended. Second, they emphasize on the benefit of reducing sodium intake even in non-hypertensive people. The DASH combination diet is consistent with other dietary recommendations. The fat content of this diet (6\% of calories from saturated fat) is similar to that of the AHA step I diet [51]. It's dairy content (approximately 3 servings/day) and calcium content (1200 $\mathrm{mg} /$ day/2100 kcal) are also similar to dietary recommendations planned to prevent osteoporosis [52]. The content of fruit and vegetable (10 servings/day) also meets the current U.S. dietary guidelines planned to prevent cancer [21]. Therefore, the DASH trial performed BP reduction may also have other benefits in terms of preventing chronic disease. Potassium is one nutrient that contributed to the effect of the fruits-and-vegetables and a combination diet. In DASH diet, the fruits-and-vegetables, and combination diets provide approximately $75 \mathrm{mmol}$ more potassium/day than the control diet (at $2100 \mathrm{kcal} / \mathrm{day}$ ). In a recent Metaanalysis shows that, an increase of $60 \mathrm{mmol}$ of potassium in hypertensive individuals was collaborated with a 4.4 $\mathrm{mmHg}$ reduction in SBP and $2.4 \mathrm{mmHg}$ reduction in DBP [53]. Diets enriched in fruits and vegetables associated with increased antioxidant activity [54]. Prior studies have shown endothelium-dependent vasodilatation can improve by antioxidants [55]. Additionally, these diets are also increased in magnesium content. In population studies, inversely related was found to dietary intake of magnesium and BP among men, [56] women, [57] and children, [58] and there was an inverse relationship between magnesium intake and risk of stroke. However, direct supplementation of magnesium had no significant effect on BP in women with low intake.

\section{Conclusions}

High BP is largely associated with chronic condition impressed both developed and developing countries, with increasing risk collaborated with the ageing the population. Multiple dietary factors affect BP homeostasis and may have desirable effects on high BP prevention and treatment. Besides the "classical" nutritional guidelines (weight loss, reduced salt intake, increased potassium intake, moderation of alcohol consumption among drinkers), there is a clear-cut evidence of the effectiveness of the DASH dietary pattern in lowering BP, particularly in hypertensive individuals. Beneficial effect of other complex dietary patterns, like the vegetarian diets and the traditional Mediterranean diet was shown in many evidences.
More research is needed to substantiate the findings obtained by observational studies or short-term intervention trials with larger randomized intervention studies. In conclusion, the role of nutrition in the prevention of high BP and its comorbiditie with high impact on public health and socioeconomic costs must not be neglected and need stronger researches than that supported by present scientific evidence.

\section{Footnotes}

Authors' Contribution: Mansuor Sharaki and Golnaz Arjmand contribute to the conception and design of the work. Search in databases, literature review and drafting the manuscript performed by Golnaz Arjamnd. Sara Rahati helped in literature review and drafting. Touran Shahraki participated in the final drifting and English edition of the manuscript. All authors read and approved the final manuscript. Supervision of work performed by Mansour Shahraki.

Funding/Support: There was no funding for this article. This article did not have any support.

\section{References}

1. World Health Organization . The world health report 2002-reducing risks, promoting healthy life. Geneva: WHO; 2002. pp.1-239.

2. MacMahon S, Peto R, Cutler J, Collins R, Sorlie P, Neaton J, et al. Blood pressure, stroke, and coronary heart disease. Part 1, Prolonged differences in blood pressure: prospective observational studies corrected for the regression dilution bias. Lancet. 1990;335(8692):765-74. [PubMed: 1969518].

3. van den Hoogen PC, Feskens EJ, Nagelkerke NJ, Menotti A, Nissinen A, Kromhout D. The relation between blood pressure and mortality due to coronary heart disease among men in different parts of the world. Seven Countries Study Research Group. N Engl J Med. 2000;342(1):1-8. doi: 10.1056/NEJM200001063420101. [PubMed: 10620642].

4. Hunt SA, Abraham WT, Chin MH, Feldman AM, Francis G, Ganiats TG, et al. ACC/AHA 2005 guideline update for the diagnosis and management of chronic heart failure in the adult-summary article: a report of the American College of Cardiology/American Heart Association Task Force on Practice Guidelines (Writing Committee to Update the 2001 Guidelines for the Evaluation and Management of Heart Failure).JAm Coll Cardiol. 2005;46(6):1116-43.

5. Kearney PM, Whelton M, Reynolds K, Muntner P, Whelton PK, He J. Global burden of hypertension: analysis of worldwide data. Lancet. 2005;365(9455):217-23. doi: 10.1016/S0140-6736(05)17741-1. [PubMed: 15652604].

6. Vasan RS, Beiser A, Seshadri S, Larson MG, Kannel WB, D’Agostino $\mathrm{RB}$, et al. Residual lifetime risk for developing hypertension in middle-aged women and men: The Framingham Heart Study. JAMA. 2002;287(8):1003-10. [PubMed: 11866648].

7. Grundy SM, Cleeman JI, Daniels SR, Donato KA, Eckel RH, Franklin BA, et al. Diagnosis and management of the metabolic syndrome: an American Heart Association/National Heart, Lung, and Blood Institute Scientific Statement. Circulation. 2005;112(17):2735-52. doi: 10.1161/CIRCULATIONAHA.105.169404. [PubMed: 16157765]. 
8. Appel LJ, Brands MW, Daniels SR, Karanja N, Elmer PJ, Sacks FM, et al. Dietary approaches to prevent and treat hypertension: a scientific statement from the American Heart Association. Hypertension. 2006;47(2):296-308. doi: 10.1161/01.HYP.0000202568.01167.B6. [PubMed: 16434724].

9. Stamler J, Rose G, Stamler R, Elliott P, Dyer A, Marmot M. INTERSALT study findings. Public health and medical care implications. Hypertension. 1989;14(5):570-7. [PubMed: 2807518].

10. Whelton SP, Chin A, Xin X, He J. Effect of aerobic exercise on blood pressure: a meta-analysis of randomized, controlled trials. Ann Intern Med. 2002;136(7):493-503. [PubMed: 11926784].

11. Hypertension Prevention Collaborative Research Group . Effects of weight loss and sodium reduction intervention on blood pressure and hypertension incidence in overweight people with high-normal blood pressure. The Trials of Hypertension Prevention, phase II. The Trials of Hypertension Prevention Collaborative Research Group. Arch Intern Med. 1997;157(6):657-67. [PubMed: 9080920].

12. Whelton PK, Appel LJ, Espeland MA, Applegate WB, Ettinger WJ, Kostis $\mathrm{JB}$, et al. Sodium reduction and weight loss in the treatment of hypertension in older persons: a randomized controlled trial of nonpharmacologic interventions in the elderly (TONE). TONE Collaborative Research Group. JAMA. 1998;279(11):839-46. [PubMed: 9515998].

13. He J, Ogden LG, Vupputuri S, Bazzano LA, Loria C, Whelton PK. Dietary sodium intake and subsequent risk of cardiovascular disease in overweight adults. JAMA. 1999;282(21):2027-34. [PubMed:10591385].

14. Tuomilehto J, Jousilahti P, Rastenyte D, Moltchanov V, Tanskanen A Pietinen P, et al. Urinary sodium excretion and cardiovascular mortality in Finland: a prospective study. Lancet. 2001;357(9259):848-51. doi: 10.1016/S0140-6736(00)04199-4. [PubMed: 11265954].

15. NHLBI . Clinical guidelines on the identification, evaluation, and treatment of overweight and obesity in adults: The evidence report. US: NIH publication; 1998.

16. Staessen J, Fagard R, Lijnen P, Amery A. Body weight, sodium intake and blood pressure. J Hypertens Suppl. 1989;7(1):S19-23. [PubMed: 2651610].

17. Shahraki M, Shahraki T, Ansari H. The effects of socio-economic status on BMI, waist:hip ratio and waist circumference in a group of Iranian women. Public Health Nutr. 2008;11(7):757-61. doi: 10.1017/S1368980007001577. [PubMed: 18194587].

18. Maddah M, Shahraki T, Shahraki M. Underweight and overweight among children in Zahedan, south-east Iran. Public Health Nutr. 2010;13(10):1519-21. doi: 10.1017/S1368980010000388. [PubMed: 20353615].

19. Shahraki T, Shahraki M, Roudbari M, Gargari BP. Determination of the leading central obesity index among cardiovascular risk factors in Iranian women. Food Nutr Bull. 2008;29(1):43-8. [PubMed:18510204].

20. Cushman WC, Cutler JA, Hanna E, Bingham SF, Follmann D, Harford T, et al. Prevention and Treatment of Hypertension Study (PATHS): effects of an alcohol treatment program on blood pressure. Arch Intern Med. 1998;158(11):1197-207. [PubMed: 9625399].

21. Whelton PK, He J, Cutler JA, Brancati FL, Appel LJ, Follmann D, et al. Effects of oral potassium on blood pressure. Meta-analysis of randomized controlled clinical trials. JAMA. 1997;277(20):1624-32. [PubMed: 9168293].

22. Berkow SE, Barnard ND. Blood pressure regulation and vegetarian diets. Nutr Rev. 2005;63(1):1-8. [PubMed: 15730229].

23. Hu FB. Dietary pattern analysis: a new direction in nutritional epidemiology. Curr Opin Lipidol. 2002;13(1):3-9. [PubMed: 11790957].

24. Eaton SB, Konner M. Paleolithic nutrition. A consideration of its nature and current implications. N Engl J Med. 1985;312(5):283-9. doi: 10.1056/NEJM198501313120505. [PubMed: 2981409].

25. Page LB, Damon A, Moellering RJ. Antecedents of cardiovascular disease in six Solomon Islands societies. Circulation. 1974;49(6):1132-46. [PubMed: 4831656].

26. Casley-Smith JR. Blood pressures in Australian aborigines. Med J Aust. 1959;46(19):627-33. [PubMed: 13656043].
27. Poulter NR, Khaw K, Hopwood BE, Mugambi M, Peart WS, Sever PS. Determinants of blood pressure changes due to urbanization: a longitudinal study. J Hypertens Suppl. 1985;3(3):S375-7. [PubMed: 2856743].

28. Fraser GE. Associations between diet and cancer, ischemic heart disease, and all-cause mortality in non-Hispanic white California Seventh-day Adventists. Am J Clin Nutr. 1999;70(3 Suppl):532S-8S [PubMed: 10479227].

29. Melby CL, Goldflies DG, Toohey ML. Blood pressure differences in older black and white long-term vegetarians and nonvegetarians. $J$ Am Coll Nutr. 1993;12(3):262-9. [PubMed: 8409080].

30. Myers $\mathrm{VH}$, Champagne CM. Nutritional effects on blood pressure Curr Opin Lipidol. 2007;18(1):20-4. doi:10.1097/MOL.0b013e328012d911. [PubMed: 17218827].

31. John JH, Ziebland S, Yudkin P, Roe LS, Neil HA, Oxford F, et al. Effects of fruit and vegetable consumption on plasma antioxidant concentrations and blood pressure: a randomised controlled trial. Lancet. 2002;359(9322):1969-74. [PubMed: 12076551].

32. Galley HF, Thornton J, Howdle PD, Walker BE, Webster NR. Combination oral antioxidant supplementation reduces blood pressure. Clin Sci (Lond). 1997;92(4):361-5. [PubMed: 9176034].

33. Panza JA, Garcia CE, Kilcoyne CM, Quyyumi AA, Cannon R3. Impaired endothelium-dependent vasodilation in patients with essential hypertension. Evidence that nitric oxide abnormality is not localized to a single signal transduction pathway. Circulation. 1995;91(6):1732-8. [PubMed: 7882481]

34. Keys A, Menotti A, Karvonen MJ, Aravanis C, Blackburn H, Buzina R, et al. The diet and 15-year death rate in the seven countries study. Am J Epidemiol. 1986;124(6):903-15. [PubMed: 3776973].

35. Willett WC, Sacks F, Trichopoulou A, Drescher G, Ferro-Luzzi A, Helsing E, et al. Mediterranean diet pyramid: a cultural model for healthy eating. Am J Clin Nutr. 1995;61(6 Suppl):1402S-6S. [PubMed: 7754995].

36. Royal College of Physicians . International Consensus StatementDietary Fat, theMediterranean Diet, and Lifelong Good Health 2000International Conference on the Mediterranean Diet London: Royal College of Physicians; 2000. Available from: http://europa.eu.int/comm/ agriculture/prom/olive/medinfo/uk_ie/consensus/index.htm.

37. de Lorgeril M, Salen P, Martin JL, Monjaud I, Delaye J, Mamelle N. Mediterranean diet, traditional risk factors, and the rate of cardiovascular complications after myocardial infarction: final report of the Lyon Diet Heart Study. Circulation. 1999;99(6):779-85. [PubMed: 9989963].

38. Trichopoulou A, Vasilopoulou E. Mediterranean diet and longevity. $\mathrm{Br}$ J Nutr. 2000;84 Suppl 2:S205-9. [PubMed: 11242471].

39. Panagiotakos DB, Chrysohoou C, Pitsavos C, Tzioumis K, Papaioannou I, Stefanadis C, et al. The association of Mediterranean diet with lower risk of acute coronary syndromes in hypertensive subjects. Int J Car diol. 2002;82(2):141-7. [PubMed: 11853900].

40. Pitsavos C, Panagiotakos DB, Chrysohoou C, Papaioannou I, Papadimitriou L, Tousoulis D, et al. The adoption of Mediterranean diet attenuates the development of acute coronary syndromes in people with the metabolic syndrome. Nutr J. 2003;2:1. [PubMed: 12740043].

41. Dontas AS, Zerefos NS, Panagiotakos DB, Vlachou C, Valis DA. Mediterranean diet and prevention of coronary heart disease in the elderly. Clin Interv Aging. 2007;2(1):109-15. [PubMed: 18044083].

42. Ferrara LA, Raimondi AS, d'Episcopo L, Guida L, Dello Russo A, Marotta T. Olive oil and reduced need for antihypertensive medications. Arch Intern Med. 2000;160(6):837-42. [PubMed:10737284].

43. Rasmussen OW, Thomsen C, Hansen KW, Vesterlund M, Winther E, Hermansen K. Effects on blood pressure, glucose, and lipid levels of a high-monounsaturated fat diet compared with a high-carbohydrate diet in NIDDM subjects. Diabetes Care. 1993;16(12):1565-71. [PubMed: 8117360].

44. Appel LJ, Moore TJ, Obarzanek E, Vollmer WM, Svetkey LP, Sacks FM, et al. A clinical trial of the effects of dietary patterns on blood pressure. DASH Collaborative Research Group. NEngl JMed. 1997;336(16):1117-24 
doi: 10.1056/NEJM199704173361601. [PubMed: 9099655].

45. Sacks FM, Svetkey LP, Vollmer WM, Appel LJ, Bray GA, Harsha D, et al. Effects on blood pressure of reduced dietary sodium and the Dietary Approaches to Stop Hypertension (DASH) diet. DASH-Sodium Collaborative Research Group. N Engl J Med. 2001;344(1):3-10. doi: 10.1056/NEJM200101043440101. [PubMed: 11136953].

46. Svetkey LP, Simons-Morton D, Vollmer WM, Appel LJ, Conlin PR, Ryan $\mathrm{DH}$, et al. Effects of dietary patterns on blood pressure: subgroup analysis of the Dietary Approaches to Stop Hypertension (DASH) randomized clinical trial. Arch Intern Med. 1999;159(3):285-93. [PubMed: 9989541].

47. Moore TJ, Svetkey LP, Lin PH, Karanja N. The DASH Diet for Hypertension. New York: Simon and Schuster; 2001.

48. Joint national committee on prevention. The sixth report of the Joint National Committee on prevention, detection, evaluation, and treatment of high blood pressure. Arch Intern Med. 1997;157(21):2413-46. [PubMed: 9385294].

49. Vollmer WM, Sacks FM, Ard J, Appel LJ, Bray GA, Simons-Morton DG, et al. Effects of diet and sodium intake on blood pressure: subgroup analysis of the DASH-sodium trial. Ann Intern Med. 2001;135(12):101928. [PubMed: 11747380].

50. NCEP . Summary of the second report of the National Cholesterol Education Program (NCEP) Expert Panel on Detection, Evaluation, and Treatment of High Blood Cholesterol in Adults (Adult Treatment Panel II). JAMA. 1993;269(23):3015-23. [PubMed: 8501844].

51. NIH . Optimal calcium intake. NIH Consensus Development Panel on Optimal Calcium Intake. JAMA. 1994;272(24):1942-8. [PubMed:
7990248]

52. US Department of Agriculture . Dietary Guidelines for Americans. 4 ed. Wishangton: US Department of Agriculture; 1995.

53. Ting HH, Timimi FK, Haley EA, Roddy MA, Ganz P, Creager MA. Vitamin $C$ improves endothelium-dependent vasodilation in forearm resistance vessels of humans with hypercholesterolemia. Circulation. 1997;95(12):2617-22. [PubMed: 9193429].

54. Joffres MR, Reed DM, Yano K. Relationship of magnesium intake and other dietary factors to blood pressure: the Honolulu heart study. Am J Clin Nutr. 1987;45(2):469-75. [PubMed: 3812346].

55. Ascherio A, Hennekens C, Willett WC, Sacks F, Rosner B, Manson J, et al. Prospective study of nutritional factors, blood pressure, and hypertension among US women. Hypertension. 1996;27(5):1065-72. [PubMed: 8621198].

56. Simons-Morton DG, Hunsberger SA, Van Horn L, Barton BA, Robson AM, McMahon RP, et al. Nutrient intake and blood pressure in the Dietary Intervention Study in Children. Hypertension. 1997;29(4):930-6. [PubMed: 9095079].

57. Ascherio A, Rimm EB, Hernan MA, Giovannucci EL, Kawachi I, Stampfer MJ, et al. Intake of potassium, magnesium, calcium, and fiber and risk of stroke among US men. Circulation. 1998;98(12):1198204. [PubMed: 9743511].

58. Sacks FM, Willett WC, Smith A, Brown LE, Rosner B, Moore TJ. Effect on blood pressure of potassium, calcium, and magnesium in women with low habitual intake. Hypertension. 1998;31(1):131-8. [PubMed: 9449404]. 